\title{
Public health and social justice: Forging the links
}

\author{
L Horn, MB ChB, DTM\&H, DCH(SA), MPhil (Applied Ethics), Diploma: International Research Ethics, PhD \\ Centre for Applied Ethics, Department of Philosophy and Division for Research Development, Stellenbosch University, South Africa
}

Corresponding author: L Horn (Ihorn@sun.ac.za)

\begin{abstract}
The purpose of this article is to explore the concept and scope of public health and to argue that particularly in low-income contexts, where social injustice and poverty often impact significantly on the overall health of the population, the link between public health and social justice should be a very firm one. Furthermore, social justice in these contexts must be understood as not simply a matter for local communities and nation-states, but in so far as public health is concerned, as a matter of global concern and responsibility. The interpretation of the scope of public health by any particular nation is I believe contingent on the current socio-political context and the conception of social or distributive justice that underpins this context. Furthermore I will argue here that the link between public health and social justice ought to be founded on a conception of social justice that adequately addresses issues of social injustice, and patterns of systematic disadvantage, that contribute to ill health and that so commonly prevail in many low- and middle-income social contexts.
\end{abstract}

S Afr J BL 2015:8(2):26-29. DOI:10.7196/SAJBL.437

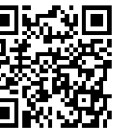

A review of the current literature quickly reveals that the answer to the question 'What is public health?' is not a straightforward one and appears influenced by many factors, not least socio-political context. ${ }^{[1]}$ 'This is understandable as one of the key points of contention in public health is the legitimate extent of the role and responsibility of the state or government in the health of its citizens. Furthermore, social justice in these contexts must be understood as not simply a matter for local communities and nation-states, but in so far as public health is concerned, as a matter of global concern and responsibility.[1]

The purpose of this article is to explore the scope of public health and to argue that particularly in low income-contexts, where social injustice and poverty often impact significantly on the overall health of the population, the link between public health and social justice should be a very firm one. 'The concept of public health is often presented as objective and without underlying value considerations. The definition of public health, as an approach to health that is concerned primarily with the health of communities or populations and delivered primarily by organisations or government rather than individuals, is generally accepted. However what is contested is the scope of what falls under the umbrella of public health and the identification of those responsible for delivering this entity, 'public health'. This is where value considerations are drawn into the discussion. The interpretation of the scope of public health by any particular nation is I believe contingent on the current prevailing sociopolitical context and the conception of social justice that underpins this context. ${ }^{[1]}$ I use the term social justice broadly, in line with Burris and Anderson, ${ }^{[2]}$ to incorporate a range of values such as 'human rights, social equality and distributive justice.[2] Furthermore I will argue here that the link between public health and social justice should be closely forged and that public health ought to be founded on a conception of social justice that adequately addresses issues of social injustice and 'patterns of systematic disadvantage' that contribute to ill health and that so commonly prevail in many lowand middle-income social contexts. ${ }^{[3]} \mathrm{A}$ detailed comparative analysis of different theories of social justice is not the focus of this paper and shall not be attempted. However, I shall support a broadly essentialist view of social justice as developed by authors such as Nussbaum, $\operatorname{Sen}^{[4]}$ and more recently Powers and Faden. ${ }^{[3]}$ I shall conclude this paper by introducing the notion, in line with cosmopolitan theorists, that affluent nations do have an obligation - founded in justice and not merely altruism or beneficence - to share the responsibility of the burden of public-health implementation in low income contexts. Due to word limitations this argument cannot be expanded here, but will be developed in a separate paper.

\section{Conceptions of public health}

One of the earliest conceptions of public health was published in 1920 by Winslow, ${ }^{[5]}$ then Professor of Public Health at Yale. This definition was one of the first attempts to define the scope of public health: ${ }^{[1]}$

'Public health is the science and art of (1) preventing disease, (2) prolonging life and (3) organised community efforts for (a) the sanitation of the environment, (b) the control of communicable infections, (c) the education of the individual in personal hygiene, (d) the organization of medical services for the early diagnosis and prevention of disease, and (e) the development of a social machinery to ensure everyone a standard of living adequate for the maintenance of health, so organizing these benefits as to enable every citizen to realize his birthright and longevity. ${ }^{[5]}$

The Institute of Medicine (IOM) in its 1988 report entitled The Future of Public Health gives a broader definition of public health. The IOM definition has three parts, namely mission, substance and organisational structure: $:^{[1,6]}$

- The mission of public health as: the fulfillment of society's interest in assuring the conditions in which people can be healthy.

- The substance of public health as: organised community efforts aimed at the prevention of disease and promotion of health. It links many disciplines and rests upon the scientific core of epidemiology.

- The organisational framework of public health: to encompass both activities undertaken within the formal structure of government and the associated efforts of private and voluntary organisations and individuals..$^{[6]}$

The Royal College of Physicians, ${ }^{[7]}$ UK defines public health as: 'The science and art of preventing disease, prolonging life and promoting 
health through organized efforts of society'. The Nuffield Council on Bioethics ${ }^{[8]}$ also uses the above definition, but adds that two notions are of particular importance when trying to define the scope of public health, namely the importance of prevention and the notion that public health is achieved by 'collective effort! $[1,7,8,9]$

The definitions presented above all appear to be fairly neutral, descriptive definitions although some do have normative elements. They all have common themes and by looking at their commonalities one can start to develop a better idea of 'What is public health?' The following are some of the themes or phrases that appear repeatedly: 'prevention of disease', 'promotion of health', 'organised effort of society', 'health of populations' or 'people', 'conditions under which people can be healthy'. Therefore a minimum conception of public health could be some form of organised or collective effort undertaken to promote the health of a community or population, particularly by preventing disease. Underlying the apparent broad agreement with this concept is considerable disagreement with respect to interpretation of the scope of public health. The main areas of contention are: Who is in fact responsible for this 'organised effort' of health promotion and disease prevention and, what is or should be the extent of that responsibility? Does it include ensuring that 'conditions exist under which people can be healthy? ${ }^{[8]}$ What should the extent and reach of the authority be, by those recognised as having this responsibility, to fulfil the goals of health promotion and disease prevention? ${ }^{[1]}$

A useful discussion of the concept of public health is presented by Dawson and Verweij. ${ }^{[10]}$ They note that Winslow's definition sets out the traditional field of public health as those activities such as water sanitation, disease surveillance, health education, etc, that can be undertaken to promote health and prevent disease. More recent definitions and discussions however, like those reflected above, do appear to be widening the field of public health to include a range of factors that may influence the conditions under which people can or cannot live healthy lives. Dawson and Verweij ${ }^{[10]}$ see this as potentially problematic. 'If we employ such an approach, any intervention aiming at improving well-being is likely to count as a matter relevant to public health. The concept of "public health" essentially just collapses into that of generating wellbeing or welfare: as a result such a concept arguably loses any useful purpose..[10] They therefore caution against defining the concept of public health too broadly. They continue to explore the concept by focusing on the two senses of 'public' in 'public health', namely: public as meaning health of populations or communities of people; and 'public' as meaning a 'collective', as in organisational group responsible for health prevention and promotion. Therefore, the 'practice of public health (roughly) consists of collective interventions that aim to promote and protect the health of the public'! ${ }^{[10]}$ These interventions are aimed at the population as a whole, rather than at individuals, and the effect of such interventions or outcome measures should be apparent at population level. However, the distribution of health within a population is as important as the overall aggregation of health improvement, as are 'the underlying social and environmental conditions that might affect the health of each member of the public'[1, 10]

The second sense of 'public' discussed by Dawson and Verweij ${ }^{[10}$ is the notion of a 'collective intervention', namely, that public health does not involve the actions of individuals but rather collective actions in the form of policies or programmes. Unlike authors proposing a particularly narrow view of public health, they concede that these collective efforts may involve both government and other organisations like non-governmental organisations (NGOs) and, to be successful often involve the cooperation and participation of members of the public themselves. ${ }^{[1]}$.

Lawrence Gostin ${ }^{[11]}$ who has written extensively in this field, states that 'the problem with an expansive view, is that public health becomes limitless, as almost everything human beings undertake affects public health. ${ }^{[10]}$ Gostin's concerns are mainly pragmatic as by adopting such a wide approach the 'field lacks precision' and 'lacks a discrete expertise'. He also notes that 'by espousing controversial issues of economic redistribution and social restructuring the field becomes highly political! ${ }^{[1,11]}$

Mark Rothstein ${ }^{[12]}$ argues against a broad agenda for public health and proposes instead a particularly narrow view which is diametrically opposite. He discusses three different approaches to public health which he describes as: 'human rights as public health', 'population health as public health', and 'government intervention as public health', rigorously supporting the last approach. ${ }^{[1]]}$ In his view health and health choices should remain predominantly the concern and domain of individuals, unless central action is required to protect lives such as in a pandemic. The human rights approach to public health is considered by Rothstein to be an inappropriately broad approach and Rothstein's objections to it are in accordance with Gostin's ${ }^{[11]}$ argument above. Rothstein states: 'Individuals trained in public health should not give up the noble struggle to ensure that every person has a minimum standard of living to support a healthy life. But this battle must be fought together with people from all disciplines and all walks of life and without using the self-defeating strategy of annexing human rights into the public health domain.[1,12]

The Nuffield Council on Bioethics published an extensive report in December 2007 entitled Public Health: Ethical Issues and devoted the first chapter largely to attempting to define the scope of public health ${ }^{[8]}$ Their discussion contrasts significantly with Rothstein's view and is situated within the context of the UK's National Health System (NHS). They note that the NHS is an important part of the UK's public health system as it is:

...considered too important to be left to private suppliers alone ... Focusing on equity and fairness considerations, there is a risk that a fully privatised approach would increase inequalities. ...The reduction of health inequalities must be one of the principal aims of public health policy. The provision of some form of public healthcare system ...is therefore a public service of exceptional value, complementing other forms of public health initiatives, such as provision of clean water. ${ }^{18]}$

This more egalitarian approach to healthcare, in general seems to result in a broader approach to public health in which the boundaries between individual healthcare and service-provision measures, aimed primarily at socioeconomic factors such as housing, and other public health initiatives, are blurred. The central obligation for public health is placed clearly at government level but other role players are not excluded. 'The role of government is to provide certain key services that should not be left to the market alone, and to establish the rules under which different agents operate in a way that is compatible with promoting health and reducing inequalities! ${ }^{[1,8]}$ 


\section{Linking public health to social justice}

Much has been written over the last two decades on the link between public health and social justice. Some authors are supportive of some conception of social justice - often a version of essentialism or capability theory - as an appropriate foundation for public health and others, such as Rothstein, ${ }^{[12]}$ are not. I believe there is always some link between social justice and public health. All nation-states have some form of political system that influences distributive justice, ranging from libertarianism to socialism and beyond, and this influences public health policy. A state or government that upholds a libertarian conception of justice, where the protection of rights to property, liberty and privacy are paramount, may well support a fairly narrow conception of public health in comparison to a government who adheres to a more egalitarian conception of social or distributive justice more generally. Alternatively a nation that pays little or no attention to the protection of human rights and civil liberties and the avoidance of social injustice is likely to promote a model of public health that is possibly paternalistic and probably autocratic.

South Africa (SA), a country that has undergone a dramatic political transition, illustrates this point well. The apartheid government's interpretation of social justice (1948 - 1994) significantly influenced the biased implementation of both health service provision and the scope of public health practice. During apartheid non-white women and children were largely confined to rural areas with limited access to health promotion and disease prevention programmes, such as antenatal care and childhood vaccination. Therefore preventable events such as high rates of infant and maternal mortality were not uncommon in these areas. ${ }^{[13,14]}$ The post-apartheid era has seen a considerable widening of both public health programmes and the scope of health services that are now delivered by the state. Even so, the scope of these services, including public health disease prevention programmes, has been highly contentious and a matter of great controversy in the recent past. The court action by the Treatment Action Campaign (TAC) ${ }^{[15]}$ regarding the very slow implementation of HIV prevention programmes including Prevention of Mother to Child Transmission (PMTCT) is a case in point.

In many other low-income countries, particularly on the African, Indian and Asian continents, the burden of disease and life expectancy is inextricably linked to poverty and persistent patterns of discrimination, most notably discrimination against women. The World Health Organization (WHO) commission report on the social determinants of health, published in 2008, confirms this link. ${ }^{[16]}$

An increasing number of scholars are making a case for forging a tight link between a theory of social justice that can adequately address the social injustices and 'patterns of systematic discrimination' that so often exist in poor or marginalised communities, and the practice of public health. ${ }^{[3]}$ Powers and Faden ${ }^{[3]}$ are such authors and they devote their book 'Social Justice: The moral foundations of public health and health policy' to this argument. They describe the 'standard view' of the moral foundation of public health as resting on 'general obligations in beneficence to promote good or welfare. ${ }^{[3]}$ Furthermore, the 'standard view' is usually understood to:

'[H]ave utilitarian commitments to bring about as much health as possible. Concerns about justice, like concerns about respect for individual liberties, are understood as ethical considerations external to the moral purpose of public health that serve to balance public health's single-minded function to produce the good of health with other right making concerns. In these discussions, justice is almost entirely presented as a distributional principle. ${ }^{[3]}$

They argue that public health cannot be focused only on outcomes but rather should be based on broader notions of well-being that 'capture what we believe are the twin moral impulses that animate public health: to improve human well-being by improving health and to do so in particular by focusing on the needs of those who are the most disadvantaged'.[3] Chapter four has as its chief focus a discussion of 'Justice, Sufficiency and Systemic Disadvantage' and highlights what is generally well accepted; that the social injustice and poverty that is so prevalent in many developing world countries fosters poor health and disease and limits well-being. ${ }^{[3,17]}$ Powers and Faden identify six dimensions of well-being which they argue matter to everyone, no matter where in the world one lives. The purpose of public health programmes and policy should be to ensure a sufficiency of wellbeing in each of these dimensions: health, personal security, self-determination, attachment, reasoning, and respect. ${ }^{[3]}$ Other scholars, such as Jennifer Prah Ruger, ${ }^{[18]}$ have recently used the essentialist sufficiency approach to social justice developed by Martha Nussbaum and Amartya $\operatorname{Sen}^{[4]}$ to expand the literature, arguing for a strengthening of the link between health delivery, in a broad sense, and social justice. Other authors have demonstrated the usefulness of Powers and Faden's ${ }^{[3]}$ 'sufficiency of well-being' theory in holistically addressing real public health problems such as fetal alcohol syndrome and human papilloma virus infection at a community level. ${ }^{[19,20]}$ What is perhaps less clear though, is not that a good theory of justice would be a useful moral foundation for public health particularly in low- and middle-income countries and communities, but rather whose moral responsibility is it to deliver on the promises articulated by such a theory?

Charles Beitz ${ }^{[21]}$ was one of the earliest scholars to argue in response to John Rawls that members of affluent societies do have obligations founded on justice, not merely humanitarian obligations or those based on beneficence, to 'share their wealth with poorer people elsewhere! ${ }^{[22]}$

Heywood and Shija ${ }^{[23]}$ have used the SA context to illustrate the enormity of the public health challenge that SA faces now, even with a constitution that is based on a comprehensive Bill of Rights and a government that is committed to introducing National Health Insurance and providing antiretroviral therapy (ART) to an estimated extra 500000 people a year who will need it. Therefore they ask the question 'Should the duty to fulfill the right to health in this context be SA's alone?'[23] In line with cosmopolitan theorists ${ }^{[2]]}$ they make the point that the extraordinary burden of disease experienced by low-income countries is not just due to local issues and corruption but 'often has historical determinants that go back centuries'. These include slavery, colonialism, the cold war and of course, in SA, apartheid. Migrant labour and gold mining contributed significantly to the current epidemiology of both tuberculosis and HIV. Heywood and Shija ${ }^{[23]}$ conclude that an internationally accepted framework and standard for global health is a 'moral legal; political and public health imperative'. Furthermore such a framework must not rely on the 'vagaries and subjective priorities of different political administrations in the USA, Canada and the EU'. 


\section{Conclusion}

What is 'public health' then? I think it is fairly easy to accept that public health is about the health of societies and communities rather than the health of individuals. Public health is also generally a public enterprise undertaken by organisations and governments. ${ }^{[10]}$ This much appears to be largely uncontested. What remains far more contentious, and inevitably influenced by some conception of social justice (however that may be conceived), is the exact scope or range of programmes and interventions that will fall under the umbrella of public health; and the role, responsibility and authority of any given entity to implement these programmes.

The argument proposed in this paper addresses three aspects of public health. The first is that the moral foundation of public health, particularly in low-income or otherwise vulnerable communities, ought to be closely linked to a broad, well-justified and appropriate concept of social justice that can serve as the bedrock for public health interventions. These interventions will prevent disease and promote health by simultaneously addressing the underlying determinants of ill health such as poverty, poor food security, lack of education and gender and race discrimination. This would mean that the scope of public health will be broader than that proposed by authors such as Dawson and Verweij, ${ }_{1}^{[10]}$ and include things like domestic violence and prevention of fetal alcohol abuse. Second, although I have not argued in favour of one specific theory of justice, as this was not the main focus of this paper, I am broadly in agreement with those theories that are essentialist in nature such as those proposed by Nussbaum and Sen, ${ }^{[4]}$ and Faden and Powers, ${ }^{[3]}$ as I believe this bottom-up, non-ideal approach is both practical and holistic. Finally, I have introduced the idea that the obligations imposed by such a theory of justice, acting as the moral foundation of public health in vulnerable and low-income communities, cannot be the responsibility of such communities or nation-states alone, but that well-resourced nations have an obligation founded on justice, not merely altruism or beneficence, to assist low- and medium-income countries to address public health issues (this is argued for elsewhere).

Acknowedgement. Prof. Anton van Niekerk as promotor of my PhD thesis from which this paper is adapted. Gail Robinson for valuable editorial assistance. The Andrew W Mellon Foundation for financial assistance to complete doctoral studies.

\section{References}

1. Horn LM. Virtue ethics in the development of a framework for public health. PhD thesis. Stellenbosch: Stellenbosch University, 2010:22-30. https://scholar.sun.ac.za/ handle/10019.1/5418. Excerpts from this paper have been taken directly from this thesis.

2. Burris S, Anderson ED. A framework convention on global health: Social justice lite, or a light on social justice? J Law Med Ethics 2010;38(3):580-93. [http://dx.doi. org/10.1111/j.1748-720x.2010.00513.x]

3. Powers M, Faden R. Social justice: The moral foundations of public health and health policy. Oxford: Oxford University Press, 2006;4:80-99,16-29.

4. Nussbaum MC, Sen AK. The Quality of Life. Oxford: Clarendon, 1993.

5. Winslow CEA. The untilled field of public health. Modern Medicine 1920;2:83.

6. Institute of Medicine. The future of public health. Washington DC: National Acadamies Press,1988. http://www.nap.edu/openbook.php?record_id=1091 (accessed 17 December 2014).

7. Faculty of Public Health. What is Public Health? London: Faculty of Public Health 2015. http://www.fph.org.uk/what_is_public_health (accessed 17 December 2014).

8. Nuffield Council on Bioethics. Public Health: Ethical Issues. London: Nuffield Council on Bioethics, 2007:6-9.

9. Horn L, Mwaluko G. Public health research ethics. In: Kruger M, Ndebele P, Horn L, eds. Research Ethics in Africa: A resource for Research Ethics Committees. Stellenbosch: SunMeDIA, 2014.

10. Dawson A, Verweij M, eds. Ethics, prevention and public health. Oxford: Oxford University Press, 2007:17-25.

11. Gostin LO. Public health, ethics, and human rights: A tribute to the late Jonathan Mann. J Law Med Ethics 2001;29(2):121-130.

12. Rothstein MA. Rethinking the meaning of public health. J Law Med Ethics 2002;30(2):144-149. [http://dx.doi.org/10.1111/j.1748-720X.2002.tb00381.x]

13. Mechanic D. Apartheid medicine. Society 1973;10(3):36-44.

14. Coovadia H, Jewkes R, Barron P, Sanders D, McIntyre D. The health and health system of South Africa: Historical roots of current public health challenges. Lancet 2009;374(9692):817-834. [http://dx.doi.org/10.1016/50140-6736(9)60951-X]

15. Treatment Action Campaign (TAC) . Open letter to minister of international relations: Intervene in Karabus caase. Cape Town:TAC, 2015. http://www.tac.org.za/community/ (accessed 17 December 2014).

16. World Health Organization. Commission on Social Determinants of Health. Closing the Gap in a Generation. Health Equity Through Action on the social Determinants of Health. Geneva: World Health Organization, 2008. http://whqlibdoc.who.int/ publications/2008/9789241563703_eng.pdf?ua=1 (accessed 20 February 2014).

17. Daniels N, Kennedy BP, Kawachi I. Why Justice is Good for our Health: The Social Determinants of Health Inequalities. Daedalus 1999;128(4):215-251. http://www. jstor.org/stable/20027594 (accessed 17 December 2014).

18. Prah Ruger J. Health and Social Justice. New York: Oxford University Press, 2010.

19. Horn L. Powers and Faden's theory of social justice applied to the problem of foetal alcohol syndrome in South Africa. Pub Health Ethics 2013;6(1):3-10.

20. Thompson A. Human papilloma virus, vaccination and social justice: An analysis of a Canadian school-based vaccine program. Pub Health Ethics 2013 6(1):11-20. [http://dx.doi.org/10.1093/phe/pht010]

21. Beitz CR. Justice and international relations. Phil Pub Affairs 1975 4(4):360-389.

22. Rawls JA. Theory of Justice. Revised ed. London: Oxford University Press, 1999.

23. Heywood M, Shija J. A global framework convention on health: Would it help developing countries to fulfil their duties on the right to health? A South African perspective. J Law Med Ethics 2010;38(3):640-646.

24. Caney S. Justice beyond borders. London: Oxford University Press, 2005:4. 